\title{
Pregnancy Outcome in Inflammatory Arthropathies - Are Population Database Studies the Right Tool?
}
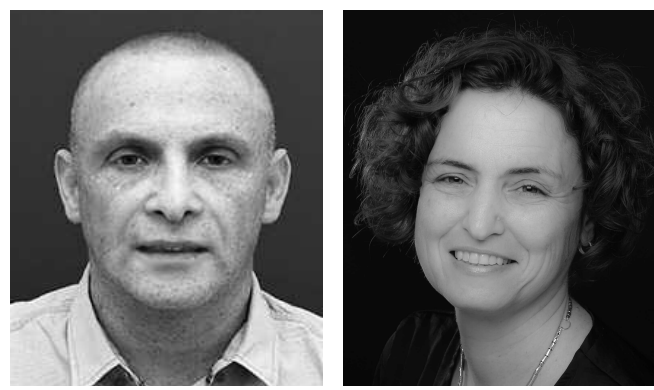

Rheumatoid arthritis (RA), psoriatic arthritis (PsA), and ankylosing spondylitis (AS) belong to the inflammatory arthropathies (IA) group. These diseases differ from one another in their underlying mechanisms, clinical phenotype, extraarticular manifestations, and in the ways they are treated. Accordingly, they are classified into different groups, such as RA versus spondyloarthropathies (SpA) including PsA and $\mathrm{AS}^{1,2}$.

However, despite these differences, IA share a similar period of onset, during the third to the sixth decades of life $3,4,5$. Accordingly, many female patients with IA are in their childbearing years and the interplay between the inflammatory arthritic disease and pregnancy is a matter of concern. To date, most of the information in this field derives from studies conducted in patients with RA, and unfortunately the gestational data regarding those who have other types of IA are scarce ${ }^{6,7,8}$.

In the current issue of The Journal, Keeling, et $a l^{9}$ addressed a very important topic of pregnancy course and outcome among patients with IA by comparing patients with $\mathrm{RA}, \mathrm{SpA}$, and healthy controls (HC) using population-based administrative data from Alberta, Canada.

The study results showed that patients with RA were at higher risk than patients with $\mathrm{SpA}$ and $\mathrm{HC}$ of experiencing hypertensive disorder during pregnancy, preterm deliveries, and cesarean deliveries. They were also more likely to give birth to small for gestational age (SGA) babies, and to deliver babies with lower birth weight compared to patients with $\mathrm{SpA}$ and to HC. Further multivariate analyses confirmed the association with hypertensive disorder and SGA. These findings are in line with several previous studies in patients with RA that showed similar pregnancy outcomes $6,7,8$.

The main contribution of this study is the gestational information about pregnancy outcomes in patients with $\mathrm{SpA}$, a topic that has been examined in only a few studies ${ }^{10,11,12}$. Contrary to the RA group, the patients with SpA in the current study had similar pregnancy courses and outcomes compared to $\mathrm{HC}$, including hypertensive disorders, SGA, preterm deliveries, and cesarean deliveries. The only significant finding was higher induction rates in the SpA group. These results are similar to a recent small, retrospective study from Toronto that did not find significant differences in maternal or neonatal outcomes between patients with PsA and matched controls ${ }^{10}$. In contrast, 3 studies suggested that $\mathrm{SpA}$ is associated with several adverse pregnancy outcomes ${ }^{10,11,12}$. A study that used data from a large prospective North American pregnancy registry found a higher risk of preterm deliveries and labors, oligohydramnios, and cesarean deliveries in patients with PsA and more infants who needed intensive care hospitalizations in patients with AS compared to $\mathrm{HC}^{11}$. Another study, from Sweden, using a nationwide population-based administrative dataset, found that patients with AS were more likely to experience more emergency and elective cesarean deliveries and preterm births, and to deliver SGA babies ${ }^{12}$. Finally, a large population-based study that used large and detailed national health registries from Sweden and Denmark found more gestational diabetes, hypertension, and cesarean deliveries among patients with psoriasis and PsA compared to controls $^{13}$.

These wide variations across the studies could result from many factors, including differences in study populations, case definitions, health systems, and study designs. The authors of the current study used a population-based administrative database as their data source. This source has several clear advantages, including the substantially large number of cases and controls (308,989 HC, $631 \mathrm{RA}$, and $2461 \mathrm{SpA}$ patients) and the lack of selection bias, because the participants arrived from different ethnic groups and regions in the province. Further, the patients were managed in different medical centers and likely represented a wide variety of disease severities. These factors increase the generalizability of the results, in contrast to single-center studies and studies using patient registries. Finally, the study includes several

See RA and SpA in peripartum, page 197

Personal non-commercial use only. The Journal of Rheumatology Copyright @ 2020 . All rights reserved. 
detailed gestational, birth, and peripartum outcomes. All of these ensured a solid base for various analyses.

However, there are several important limitations caused by this study's reliance on administrative data. The lack of information about relevant confounders such as obesity, smoking, and education level might have influenced the investigated outcomes. Obese pregnant women are more likely to experience pregnancy and perinatal complications, and these adverse outcomes are amplified with the level of obesity ${ }^{14}$. Smoking during pregnancy is a risk factor for several outcomes including preeclampsia, miscarriage, stillbirth, low birth weight, and preterm birth ${ }^{15}$. Finally, education level may have an influence on the awareness of the significance of a healthy pregnancy, and accordingly could correlate with the degree of care during this period. It is expected that the inclusion of these confounders in the analysis would have resulted in weakening of significant associations between the disease and adverse pregnancy outcomes. However, these associations were demonstrated mainly in the RA and not in the SpA group and hence the lack of inclusion of these confounders could have a significant effect on the results of the RA but not of the SpA group.

Another important aspect to consider is the effect of disease activity on pregnancy outcomes. Several previous studies showed that the level of IA disease activity during pregnancy might play a role in gestational outcomes. In a nationwide prospective cohort study, Brouwer, et al found 28 miscarriages among 162 RA pregnancies ${ }^{16}$. Patients with a higher disease activity level (by 28-joint count Disease Activity Score) had a greater tendency toward miscarriages. Bharti, et al found that an increase in Health Assessment Questionnaire-Disability Index (HAQ-DI) was associated with an elevated risk for preterm delivery and SGA among 440 women with RA ${ }^{17}$. Smith, et al showed that an increased HAQ score was associated with preterm delivery in patients with PsA, and high Routine Assessment of Patient Index Data 3 score with cesarean delivery ${ }^{11}$. Finally, Yang, et al demonstrated that severe psoriasis was associated with having low birth weight babies compared to mild psoriasis ${ }^{18}$. As expected by the design of the study that relied on administrative data, which does not include detailed information on disease activity measures, these analyses were not performed in the Keeling, et al study.

An important issue that may explain the discrepancy with other studies is related to the accuracy of case definition. Inclusion of patients with accurate diagnosis is a basic requirement for every study. Accurate diagnosis in general in medicine and particularly in rheumatology is a challenging task that relies on many factors such as the experience of the specialist. The diagnostic codes in this study were assigned by different physicians and not necessarily by rheumatologists. This may have resulted in misclassification of patients. International Classification of Diseases, 9th ed (ICD-9) and 10 were used as the tool for identification and classification of the patients with IA. However, ICD-9 and 10 are coding methods and not exclusive rheumatologic classification criteria, which may explain how some patients received both a diagnosis of RA and one of SpA. The authors decided arbitrarily to include these patients in the RA group. The lack of additional information of the validity of the ICD codes in the current database limits the ability of the readers to estimate the level of misclassification.

In addition, Keeling, et $a l^{9}$ combined different types of $\mathrm{SpA}$ as well as patients with psoriasis in the SpA group. This heterogeneous group of different diseases may have resulted in the lack of association between SpA and adverse pregnancy outcomes. Psoriasis is an inflammatory skin disease affecting $2-3 \%$ of the population ${ }^{19}$. The prevalence of SpA ranges from $0.4 \%$ to $2 \%$ in the general population ${ }^{20}$. This means that patients with psoriasis probably dominated the group of SpA in this study. Psoriasis severity ranges widely. The majority of patients tends to have a mild disease, while only about a third of patients have moderate to severe psoriasis, which tends to be associated with comorbidities ${ }^{21}$. Further, patients with psoriasis or PsA are not necessarily similar; only $20-30 \%$ of patients with psoriasis develop $\mathrm{PsA}^{22}$. A previous study comparing patients with psoriasis without arthritis to those with psoriasis and PsA found more comorbidities and combined systemic treatment such as biologic drugs in the PsA group ${ }^{23}$. Given that in this study the investigators could not differentiate between psoriasis and PsA using ICD-9 codes, it is possible that patients with mild psoriasis without IA were a substantial part of the SpA group. Taken together, all of these may have led to better pregnancy outcomes in the SpA group.

Keeling, et al showed more adverse gestational outcomes in the RA but not in the SpA group compared to controls ${ }^{9}$. The way of establishing this conclusion is the heart of the matter. There is a genuine need for further large population-based studies that will address these issues. However, this requires a preliminary process of validation of patients' diagnoses, focusing on patients with IA, and inclusion of all the relevant confounders.

\footnotetext{
ARI POLACHEK, MD, Department of Rheumatology, Tel Aviv Sourasky Medical Center, Sackler Faculty of Medicine, Tel Aviv University, Tel Aviv, Israel; LIHI EDER, $\mathrm{MD}, \mathrm{PhD}$, Department of Medicine, University of Toronto, Women's College Research Institute, Women's College Hospital, Toronto, Ontario, Canada.
}

Address correspondence to Dr. A. Polachek, Department of Rheumatology, Sourasky Medical Center, Sackler Faculty of Medicine, Tel-Aviv University, 6 Wizeman St., Tel Aviv 64239, Israel. E-mail: arikpolachek@yahoo.com 


\section{REFERENCES}

1. Aletaha D, Neogi T, Silman AJ, Funovits J, Felson DT, Bingham CO 3rd, et al. 2010 Rheumatoid arthritis classification criteria: an American College of Rheumatology/European League Against Rheumatism collaborative initiative. Arthritis Rheum 2010; 62:2569-81.

2. Rudwaleit M, van der Heijde D, Landewé R, Akkoc N, Brandt J, Chou CT, et al. The Assessment of SpondyloArthritis International Society classification criteria for peripheral spondyloarthritis and for spondyloarthritis in general. Ann Rheum Dis 2011;70:25-31.

3. Wilson FC, Icen M, Crowson CS, Gabriel SE, Kremers HM. Time trends in epidemiology and characteristics of psoriatic arthritis over 3 decades: a population-based study. J Rheumatol 2009;36:361-7.

4. Reveille JD, Weisman MH. The epidemiology of back pain, axial spondyloarthritis and HLA-B27 in the United States. Am J Med Sci 2013;345:431-6.

5. Crowson CS, Matteson EL, Myasoedova E, Michet CJ, Ernste FC, Warrington KJ, et al. The lifetime risk of adult-onset rheumatoid arthritis and other inflammatory autoimmune rheumatic diseases. Arthritis Rheum 2011;63:633.

6. Wallenius M, Salvesen KÅ, Daltveit AK, Skomsvoll JF. Rheumatoid arthritis and outcomes in first and subsequent births based on data from a national birth registry. Acta Obstet Gynecol Scand 2014;93:302-7.

7. Kishore S, Mittal V, Majithia V. Obstetric outcomes in women with rheumatoid arthritis: Results from Nationwide Inpatient Sample Database 2003-2011. Semin Arthritis Rheum 2019 Mar 23 (E-pub ahead of print).

8. Lin HC, Chen SF, Lin HC, Chen YH. Increased risk of adverse pregnancy outcomes in women with rheumatoid arthritis: a nationwide population-based study. Ann Rheum Dis 2010;69:715-7.

9. Keeling SO, Bowker SL, Savu A, Kaul P. A population-level analysis of the differing effects of rheumatoid arthritis and spondyloarthritis on peripartum outcomes. J Rheumatol 2020;47:197-203.

10. Polachek A, Polachek Shlomi I, Spitzer K, Pereira D, Ye JY, Chandran V, et al. Outcome of pregnancy in women with psoriatic arthritis compared to healthy controls. Clin Rheumatol 2019;38:895-902.

11. Smith CJF, Bandoli G, Kavanaugh A, Chambers CD. Birth outcomes and disease activity during pregnancy in a prospective cohort of women with psoriatic arthritis and ankylosing spondylitis. Arthritis Care Res 2019 May 10 (E-pub ahead of print).

12. Jakobsson GL, Stephansson O, Askling J, Jacobsson LT. Pregnancy outcomes in patients with ankylosing spondylitis: a nationwide register study. Ann Rheum Dis 2016;75:1838-42.
13. Bröms G, Haerskjold A, Granath F, Kieler H, Pedersen L, Berglind IA. Effect of maternal psoriasis on pregnancy and birth outcomes: a population-based cohort study from Denmark and Sweden. Acta Derm Venereol 2018;98:728-34.

14. Scott-Pillai R, Spence D, Cardwell CR, Hunter A, Holmes VA. The impact of body mass index on maternal and neonatal outcomes: a retrospective study in a UK obstetric population, 2004-2011. BJOG 2013;120:932.

15. Committee on Underserved Women, Committee on Obstetric Practice. Committee Opinion No. 721: Smoking cessation during pregnancy. Obstet Gynecol 2017;130:e200.

16. Brouwer J, Laven JS, Hazes JM, Dolhain RJ. Brief report: miscarriages in female rheumatoid arthritis patients: associations with serologic findings, disease activity, and antirheumatic drug treatment. Arthritis Rheumatol 2015;67:1738-43.

17. Bharti B, Lee SJ, Lindsay SP, Wingard DL, Jones KL, Lemus H, et al. Disease severity and pregnancy outcomes in women with rheumatoid arthritis: results from the Organization of Teratology Information Specialists Autoimmune Diseases in Pregnancy project. J Rheumatol 2015;42:1376-82.

18. Yang YW, Chen CS, Chen YH, Lin HC. Psoriasis and pregnancy outcomes: a nationwide population-based study. J Am Acad Dermatol 2010;64:71-7.

19. Gelfand JM, Weinstein R, Porter SB, Neimann AL, Berlin JA, Margolis DJ. Prevalence and treatment of psoriasis in the United Kingdom: a population-based study. Arch Dermatol 2005; 141:1537-41.

20. Bakland G, Nossent HC. Epidemiology of spondyloarthritis: a review. Curr Rheumatol Rep 2013;15:351.

21. Yeung H, Takeshita J, Mehta NN, Kimmel SE, Ogdie A, Margolis DJ, et al. Psoriasis severity and the prevalence of major medical comorbidity: a population-based study. JAMA Dermatol 2013;149:1173-9.

22. Mease P, Gladman D, Papp K, Khraishi MM, Thaçi D, Behrens F, et al. Prevalence of rheumatologist diagnosed psoriatic arthritis in patients with psoriasis in European/North American dermatology clinics. J Am Acad Dermatol 2013;69:729-35.

23. Pérez-Plaza A, Carretero G, Ferrandiz C, Vanaclocha F, Gómez-García FJ, Herrera-Ceballos E, et al. Comparison of phenotype, comorbidities, therapy and adverse events between psoriatic patients with and without psoriatic arthritis. Biobadaderm registry. J Eur Acad Dermatol Venereol 2017;31:1021-8.

J Rheumatol 2020;47:161-3; doi:10.3899/jrheum.190631 